\title{
Study on Teaching Value of College English Teachers under the Background of the "Belt and Road" Initiative
}

\author{
Li Wang \\ Xi'an Peihua University, Xi'an, Shaanxi, 710125, China
}

Keywords: the Belt and Road Initiative; colleges and universities; college English teachers; teaching; value

\begin{abstract}
With the continuous development of China's social economy, English teaching becomes increasingly important. Particularly, in the new situation where President Xi Jinping proposed the strategy of the "Belt and Road" Initiative, the communication and exchange between China and countries or regions along the line become closer and closer, and the teaching value of college English teachers also becomes higher accordingly. In this context, college English teachers are expected to strengthen their consciousness of innovation in English teaching reform to continuously promote the improvement of English project teaching quality, so as to implement the strategy of the "Belt and Road" Initiative better via English education. This paper covers information on the "Belt and Road" Initiative, discusses the teaching value of college English teachers to trade under the "Belt and Road" Initiative, and proposes some measures for realizing the teaching value of college English teachers under the background of the "Belt and Road" Initiative.
\end{abstract}

\section{Introduction}

English, as an important basic subject, is of high practicalness. Thanks to continuous development of economy and society, and continuous improvement of the level of globalization, the situation of global economy and trade has been greatly improved. The speaking right of China, the second largest economic entity in the world, has become bigger and bigger in the development process of international economy and trade. The launch of "the Belt and Road Initiative" strategy is of great strategic importance to the economic development of countries and regions along the line. In the strategy of "the Belt and Road Initiative", stress is laid on both the construction of economy, finance and infrastructure and communication of English language cultures. Since English is a common language used most widely in the world, the role of college English teachers in teaching is particularly important under the background of "the Belt and Road Initiative", and college English teachers are bound to play a more significant part in the construction of "the Belt and Road Initiative".

\section{Introduction to "the Belt and Road Initiative"}

Developed by ancient China, the Silk Road mainly refers to a land economic trade route linking countries and regions in Asia, Africa and Europe with China. In the very beginning, porcelains and silk cloths that were China's featured products were exported via this route. Afterwards, it was gradually developed into an important channel for the eastern and western countries to communicate and exchange with each other about economy, culture and politics. In the mid-nineteenth century, a German scholar named Richthofen called the vital communication line linking China with Central Asia and India for silk trade from 114BC to 127BC the Silk Road in his book titled China first. By transportation form, the Silk Road consists of land silk road and maritime silk road. The land silk road started from two ancient capitals of China (Luoyang and Chang'an), ran through Liangzhou, Dunhuang, Afghanistan and Syria, and ended in the city of Rome nearby the Mediterranean, of which the total length reached up to 6,440km. The maritime silk road started from China's South-East coastal areas, ran through Indo-China Peninsula, the Indian Ocean, and the Red Sea, and ended in 
East Africa and Europe, which was a key seaway linking China and other countries around the world for trade and cultural exchange. Nowadays, the global economic and political situation is very complicated, the global economy and trade are faced with tough challenge, and all countries around the world are confronted with great hindrance. Through the high-speed development of four decades since the implementation of the reform and opening-up policy, the link between China and the global economy becomes increasingly close. To implement the basic state policy of reform and opening-up better, develop a new situation of opening up comprehensively, and boost the global economy, President Xi Jinping proposed the strategy of "the Belt and Road Initiative" that follows the trend of worldwide economy uniformity and multi-polarization and cultural diversity in 2013, with a view to facilitate efficient and rational allocation of resources of the countries and regions along the line, promote various markets to fuse with each other more deeply, realize worldwide international cooperation and development of economic and trade relations, and make a contribution to peaceful global development. Meanwhile, "the Belt and Road Initiative" also provides a perfect top-level design for boosting China's open economic system in the new era and further deepening reform and development, which is sure to promote harmonious development of China's economy and society.

\section{Important Teaching Value of College English Teachers to Trade via "the Belt and Road Initiative"}

The implementation of the strategy of "the Belt and Road Initiative" is of great strategic significance to and has far-reaching effect on integrated development of China's economy and society, world economy and trade, economic and social development of the countries and regions along the line, and peaceful global development. As a common language used most widely around the world, English has been playing an important role in global trade, and also is bound to show high value in the development of economy and trade through "the Belt and Road Initiative". College English teachers with high teaching competency also are of great value to trade through "the Belt and Road Initiative". The college English teachers of Chinese colleges and universities can make concerted effort to contribute to communication and exchange between China and other countries in the process of economic and trade cooperation via "the Belt and Road Initiative", and also provide language support to the development of the integration of world economy. Specifically, the teaching value of college English teachers to trade via "the Belt and Road Initiative" is mainly reflected from the following aspects:

\subsection{College English teachers can promote scientific and technological knowledge exchange required by economy and trade via "the Belt and Road Initiative" by teaching activities}

With the advent of the era of knowledge-driven economy, the development of global economy becomes more dependent on new science and technology. The countries and regions along the line can be said to have their strong points in respect of research and application of science and technology. Only when these countries and regions deeply communicate and complement with each other about the application of knowledge of science and technology, these countries and regions can obtain more economic benefits and social benefits. Nowadays, scientific and technological communication and trade take up a large proportion in economic and trade activities via "the Belt and Road Initiative". English is a language used most widely in the world. College English teachers are supposed to train students to grasp more knowledge of English for science and technology via teaching activities, so that China can bring its superiority in English into full play in scientific technological exchange and trade with countries and regions along the line. In this way, scientific and technological information can be passed on timely, accurately and completely, and we can keep abreast of new developments related to knowledge of science and technology of the countries and regions along the line. In other words, as long as we effectively communicate and complement with the countries and regions about the implementation of new technology and put the new technology into use, the countries and regions along the line are bound to obtain more economic benefits and social benefits. 


\subsection{College English teachers can reduce the probability of economic and trade conflict via teaching activities}

In foreign economic relations and trade, English is considered to be a common language of most importance, and it is closely related to the global economic and trade rules and practice. Global economic and trade activities involve a large sum of capital transaction, considerably rigorous commercial operation logic, and diversified economic behavior, latest products and industries, which requires that the global economic and trade language should be rigorous, advanced and practical. College English teachers should focus on pertinence, accuracy and extension of language when teaching students, so as to truly satisfy the requirements of global economic and trade activities. In foreign trade, the large vocabularies of English comply with the diversified expressive form of the style of global trade language. The specialized vocabularies for foreign trade of foreign trade English can satisfy the accuracy of foreign trade language. College English teachers should coin more words or phrases satisfying the actual requirements of foreign trade by extending, creating or even mixing related English vocabularies according to the requirements of foreign trade, so as to comply with the commercial behaviors in the process of international trade and transaction. Accurate expression of foreign trade English can satisfy the requirement of legal documents for accuracy, so as to avoid any ambiguity and even dispute in international trade and transaction due to language barrier.

\subsection{College English teachers can make contributions to formulation of unified terms of economic and trade activities with the countries and regions along the line}

With the advancement of the strategy of "the Belt and Road Initiative", more and more economic and trade activities proceed among the countries and regions along the line. College English teachers can contribute to form a unified exchange language for the economic and trade activities by teaching activities, so that a wider unified English communication and exchange platform can be built and conflicts due to language barrier can be avoided.

\subsection{College English teachers can make contributions to the formation of unified cultural background of economic and trade activities with the countries and regions along the line}

With the advancement of the strategy of "the Belt and Road Initiative", the countries and regions along the line have reached a consensus, namely cooperation and mutual benefits. College English will play an important role in exchange of English culture and English thinking for the economic and trade cooperation with the countries and regions along the line. The increasingly frequent English communication and exchange during the economic and trade activities with the countries and regions along the line promote cultural exchange and thinking communication among the countries and regions along the line, enhance the mutual understanding among the countries and regions along the line, and contribute to the formation of economic and trade atmosphere among the countries and regions along the line. Only when economic and trade negotiation is conducted via equal communication and conversation with a unified language, results satisfying all parties can be obtained, the economic development and opening up of countries and regions related to "the Belt and Road Initiative" can be promoted, and the harmonious development of interrelations among the related countries and regions can be enhanced.

\section{Advices on Realization of Teaching Value of College English Teachers under the Context of "the Belt and Road Initiative"}

\subsection{To promote impartment of theoretical English knowledge}

In the implementation of classroom English teaching, college English teachers should conduct impartment of basic theoretical knowledge well, and practical teaching should be based on good command of theoretical knowledge. In view of this, college English teachers should focus on economic and trade communication for "the Belt and Road Initiative" in English teaching, and enhance teaching of theoretical knowledge constantly. For example, I impart textbook knowledge by 
personal example as well as verbal instruction, and also ask students to discuss and study around the theoretical knowledge they have learned, so that they can digest their comprehension of the learned knowledge. With such a teaching mode, teachers can control the pace of teaching, but also student's dominant role can be completely reflected.

\subsection{To lay stress on practical teaching}

In addition to efficient theoretical teaching, college English teachers also should guide students to do practical learning in relation to the imparted content, so that students can digest and absorb the learned knowledge well. In a sense, practical activities are helpful for students to grasp knowledge. For example, I will carry out classroom English teaching in two parts. One part is about theoretical knowledge impartment, and the other is to have students participate in practice in the form of scenario simulation. Scenario simulation usually is dominated by students, which can cover scenarios related to our daily life and state affairs. The purpose of scenario simulation is to train students to apply theoretical knowledge by means of scenario simulation. Particularly, in the context of the implementation of the strategy of "the Belt and Road Initiative", we can ask students to act as persons from different countries and simulate business negotiation. In this way, students can comprehend the important value of "the Belt and Road Initiative", and understand specialized English knowledge better.

\subsection{To focus on team development of English teachers}

With the full implementation of "the Belt and Road Initiative", the demand for high-level business English talents increases rapidly. Thus, we should attach importance to team development of college English teachers while making efforts to cultivation of specialized English talents. I suggest that we should establish a new media information development platform for business English to help teachers learn about enterprises' demands, the development of the specialty, and research and development of teaching materials. Meanwhile, we also should seize good opportunities to establish cooperative relationship with universities and enterprises involving in "the Belt and Road Initiative", and provide college English teachers with chances to improve their professional ability by means of visiting, taking a temporary post or volunteering as teacher. Only by this, we can build a high-level team of international business English teachers, to satisfy the requirements of economic and trade exchange under "the Belt and Road Initiative".

\section{Conclusion}

In brief, at the moment China's social economy constantly develops, the implementation of "the Belt and Road Initiative" is of great significance to the development of China's economy and trade, and the harmonious development of the countries and regions along the line. The teaching mode of college English teachers is of great value to the global trade system, and also can play an outstanding role in trade under "the Belt and Road Initiative", so as to provide strong language support to the implementation of "the Belt and Road Initiative". In other words, for the economic and trade development of the countries and regions under "the Belt and Road Initiative", college English teaching can contribute to the formation of rational expression of English language of economic trade under "the Belt and Road Initiative", and also is helpful to prevent conflicts due to language barrier. The value of college English teachers under the background of "the Belt and Road Initiative" lies in that they can contribute to the formation of unified thinking and culture base, and make bigger contributions to the improvement of China's economic and trade level and the economic development of the countries and regions along the line.

\section{References}

[1] Qin Xuebing. Study on the Role of English as Common Language in Foreign Trade in Guangxi under the Background of the Belt and Road Initiative, New Silk Road Horizon, 2015 (24). 
[2] Bao Wenxin. Chance and Development Approach of Business English Teaching under the Background of "the Belt and Road Initiative", Journal of Language and Literature Studies, 2016 (3).

[3] Yang Linlin. Study on Characteristic Construction of Business English Specialty Integrating Employment and Entrepreneurship under the Background of "the Belt and Road Initiative", Education Modernization, 2016 (15).

[4] Qin Jiabao. Discussion on Promoting Effect of English on Multicountry Trade under the Belt and Road Initiative, Chinese and Foreign Communication, 2017 (1). 